Meta

Journal des traducteurs

Translators' Journal

\title{
What Every Client Wants? (Re)mapping the Trajectory of Client Expectations Research
}

\section{Jonathan Downie}

Volume 60, numéro 1, avril 2015

URI : https://id.erudit.org/iderudit/1032398ar

DOI : https://doi.org/10.7202/1032398ar

Aller au sommaire du numéro

\section{Éditeur(s)}

Les Presses de l’Université de Montréal

ISSN

0026-0452 (imprimé)

1492-1421 (numérique)

Découvrir la revue

Citer cet article

Downie, J. (2015). What Every Client Wants? (Re)mapping the Trajectory of Client Expectations Research. Meta, 60(1), 18-35.

https://doi.org/10.7202/1032398ar

\section{Résumé de l'article}

Depuis la fin des années 1980, on a cherché à mieux comprendre ce que les orateurs, les publics et les organisateurs de conférence attendent des interprètes avec lesquels ils travaillent. L'objectif de cet article est donc de fournir un résumé critique de la recherche dans ce domaine, dans le but de permettre une meilleure compréhension de ces attentes et des approches adaptées pour les analyser de manière détaillée. Contrairement à Kurz (2001), qui a structuré son article autour des contributions de chaque auteur, ce texte offre une synthèse chronologique des publications sur les attentes des clients. Il permet ainsi de voir le développement historique de la compréhension des attentes des clients, ainsi que la diminution du nombre de publications au cours de la première décennie de ce millénaire. Nous présentons des raisons possibles de cette diminution et une explication des divergences entre les publications récentes et celles qui ont été publiées dans les autres périodes. Ces différences, surtout la division faite entre les attentes génériques et celles qui sont spécifiques à un évènement donné, offrent un point de départ pour la recherche à venir. 


\title{
What Every Client Wants? (Re)mapping the Trajectory of Client Expectations Research
}

\author{
JONATHAN DOWNIE \\ Heriot-Watt University, Edinburgh, United Kingdom \\ Jdd3@hw.ac.uk
}

\begin{abstract}
RÉSUMÉ
Depuis la fin des années 1980, on a cherché à mieux comprendre ce que les orateurs, les publics et les organisateurs de conférence attendent des interprètes avec lesquels ils travaillent. L'objectif de cet article est donc de fournir un résumé critique de la recherche dans ce domaine, dans le but de permettre une meilleure compréhension de ces attentes et des approches adaptées pour les analyser de manière détaillée. Contrairement à Kurz (2001), qui a structuré son article autour des contributions de chaque auteur, ce texte offre une synthèse chronologique des publications sur les attentes des clients. II permet ainsi de voir le développement historique de la compréhension des attentes des clients, ainsi que la diminution du nombre de publications au cours de la première décennie de ce millénaire. Nous présentons des raisons possibles de cette diminution et une explication des divergences entre les publications récentes et celles qui ont été publiées dans les autres périodes. Ces différences, surtout la division faite entre les attentes génériques et celles qui sont spécifiques à un évènement donné, offrent un point de départ pour la recherche à venir.
\end{abstract}

\section{ABSTRACT}

Since the late 1980s, scholars have sought to understand what it is that speakers, audience members or conference organisers want from the interpreters with whom they work. The aim of this paper is to provide a critical review of the work that has taken place to understand these expectations, with a view to fostering a greater understanding of both the expectations of clients and how these expectations could be explored in a more nuanced fashion. Unlike Kurz (2001), who chose to provide an author-centred summary, publications are examined in this paper in chronological order, allowing the historical development of this area of research to be clearly seen. This structure also draws attention to the relative reduction in the number of publications on client expectations published in the first decade of the current millennium. This paper gives possible reasons for this reduction in publication frequency, followed by a detailed exploration of how more recent publications in this area differ from those published in earlier periods. These differences, and most notably the move towards dividing expectations into different categories, representing stereotypical and event-specific requirements of interpreters, are presented as offering a valuable starting point for future research.

\section{MOTS-CLÉS/KEYWORDS}

Attentes des usagers, sondage, sociologie de l'interprétation, recherche qualitative fondée sur un questionnaire, public cible

User expectations, survey research, sociology of interpreting, questionnaire-based quality research, target audience 


\section{Introduction}

Since the late 1980s, scholars have sought to understand what it is that speakers, audience members or conference organisers want from the interpreters with whom they work. Danica Seleskovitch's dictum that "the chain of communication does not end in the booth" (1986: 236) pointed to the social and commercial reality of conference interpreting - interpreting is always provided for someone. This view therefore underlined the need for researchers to take into account the felt needs of this "someone" whether they be diplomats, doctors, politicians or businesspeople, and underpinned a wide and varied stream of work on the expectations that clients have of the interpreters they work with. At the beginning of the last decade, Ingrid Kurz (2001) furnished the field with a seminal author-centred summary of the work that had taken place up until that point in this area. This paper not only seeks to update the work of Kurz by providing a critical summary of the work that has gone on since her paper was published but, by providing a chronological rather than author-centred review of previous work, it attempts to map the historical trajectory of this area of Interpreting Studies.

This paper will therefore begin with a brief discussion of the justifications given for work on client expectations and will contrast these to the concerns expressed by scholars that such work may be of limited use. Following this discussion, there will be an account of the history of client expectation studies, split into three parts. The first part will plot early attempts at analysing client expectations and will cover work from Kurz's (1989) paper, which has been seen as one of the earliest attempts at discovering what clients want (Kurz 2001: 396), to Vuorikoski's (1998) seminal metaanalysis of some of the previous studies. The idea of providing a meta-analysis of previous client expectations work and indeed, many of the concerns raised by Vuorikoski would find resonance in Kurz (2001), which to this day still stands as the most thorough review of client expectations research available. So important is this paper for understanding the trajectory of the field, and the theoretical and methodological issues arising in it, that it will be given its own dedicated section in this paper. The last section of the historical review of client expectations work will cover the period from the publication of Kurz's (2001) literature review to the present day, a period which saw both the marked reduction in the number of works published in English and French on client expectations in conference interpreting and the rise of the use of other methods to understand the social contexts in which interpreters work.

The last section of the historical overview will pay special attention to the work of two scholars that would seem to run counter to both the general pattern of research in the past 12 years and the general analytical and methodological trends delineated in the rest of the historical overview. The work of these two Turkish scholars, Ebru Diriker (2004) and Şeyda Eraslan (2008; 2011), is a fundamental challenge to the prevailing interpretations of client expectations data by suggesting that the data hitherto available described only one level of a far more complex set of expectations shaped not only by the contextual variables at play in a given interpreting situation but also by the existence of a stereotypical view of interpreters. The paper will then conclude with a discussion of how the work of these two scholars may be applied to future work on client expectations. 


\section{Rationales for client expectations research?}

Aside from the aforementioned quote from Seleskovitch, researchers investigating client expectations have tended to produce very closely related justifications for their work. Kurz, for instance, justified her work on client expectations with several quotations from then-leading scholars who insisted that the target audience is a vital component in interpreting as it is for them that the interpreting is produced (Kurz 1993: 13-14). To this justification she added the assertion that "there is no certainty that the ratings given by ... interpreters yield a true picture of user expectations" (1993: 14). This suggests a need to ascribe at least some importance to the views of those who will commission or use interpreting. She would go on to repeat much the same rationale in her seminal review of literature in user expectations, adding the argument that verifying whether interpreters' views of quality are similar to those of their clients may prove useful in training and in negotiations with clients (Kurz 2001: 394).

Mack and Cattaruzza (1995) justified their study from a more theoretical angle but still in much the same vein. Taking skopos theory as their starting point, they saw user expectation studies as providing a means to learn more about the "highly dishomogenous interlinguistic and intercultural settings" (1995: 38) in which interpreting takes place and which in turn produce different reactions to the interpreting provided. This justification is very similar to the one given by Vuorikoski (1998: 189-190, 193) who argued that user studies, when carried out with sufficient numbers and sufficient depth, could eventually lead to a situation where all those involved in the interpreting event understand what their role is and what is required of them.

What seems to be missing from all of these justifications is any discussion of how realistic or workable these expectations might be. This perceived lack of a critical stance towards client expectations has been at the core of the arguments made by some scholars who question the usefulness of investigating client expectations. Shlesinger, for instance, pointed out that interpreting users need interpreting precisely because they do not have full understanding of the source language and it was therefore quite apt to ask whether they know "what's good for them" (1994: 126). Much the same point is advanced by Chiaro and Nocella who argue that "the special nature of interpreting makes its evaluation difficult for people who consume this service but know very little about it" (2004: 281).

Yet the views of scholars researching client expectations and those doubting the usefulness of such work are not actually in fundamental disagreement. Chiaro and Nocella's (2004: 281) point that clients lack familiarity with interpreting and therefore will have difficulty evaluating it bears striking resemblance to Mack and Cataruzza's view that the lack of clarity in their results may be attributable to "difficulties experienced by listeners in assessing SI ... in categories generally irrelevant to their everyday life" (1995: 45). As the rest of this paper will show, a significant proportion of the published work on client expectations has acknowledged, in one way or another, that client expectations and even client responses to interpreting are not objective evaluations of the quality of the interpreting produced. Quite the contrary, as the rest of this paper will discuss, much of the research produced has sought, in one way or another, to discover the factors that affect the views of clients, many of which may lie outside the boundaries of the actual interpreting they hear or even the conference they attend. 
Researchers investigating client expectations have also justified their work with appeals to the need to increase understanding of the contexts in which interpreters will carry out their work (Kurz 2001: 404). In this light, whether clients hold expectations that are reasonable or theoretically justifiable is beside the point. What is much more important is to increase the understanding of what these expectations are, how they might have arisen and the effect they might have on the treatment and behaviour of interpreters. As the following historical outline of work in client expectations will suggest, this progression from describing expectations to understanding their causes and effects is evident in the progression of client expectations research.

\section{A History of Client Expectation Studies}

This section will focus on those papers and monographs where researchers have sought to examine what clients expect in authentic interpreting contexts by carrying out research during interpreted conferences. Its scope will also be limited to papers, monographs and theses published in English and French, the working languages of the author. While this does limit its scope somewhat, discussions with scholars present at the IPCITI 2011 conference in Edinburgh, where an early version of this review was delivered as part of a presentation on modelling client expectations, suggested that much of what can be said about material published in these languages can be applied with equal force to work in other languages too, especially work published in Europe. In order to understand this work, one must first explore the differences between this kind of work and related work that has sought to understand the views of interpreting clients, most notably through eliciting their views of interpreting they have received - as in a study by Daniel Gile (1990) - or through investigating their views of interpreting in a more general sense - as exemplified in a study by Lidia Meak (1990).

\subsection{Early Attempts at Client Expectation Analysis: Innovation and Inconsistency}

According to Kurz's (2001: 398) report on survey work, which will be examined in detail in a later section, the earliest paper to examine what clients want from interpreters is Kurz (1989). In this paper, Kurz borrowed eight items that had first been used in Bühler's (1986) investigation of the criteria used by members of AIIC - the International Association of Conference Interpreters - to judge whether a candidate was deserving of membership. These criteria: native accent, pleasant voice, fluency, logical cohesion, sense consistency, completeness, correct usage of grammar, and correct terminology were used as survey items and ranked by clients at a medical conference on a four-point scale according to their importance for high quality interpreting (Kurz 1989: 144). The sample size was larger than some of the clients' expectations work that would come later, as 47 surveys were returned (Kurz 1989: 147). The results of this and her later studies showed slight variations in the importance given to these items by different user groups, with attendees at a Council of Europe meeting $(\mathrm{N}=48)$ showing the strongest preference for "use of correct terminology" and "completeness of interpretation" and participants at an engineering conference $(\mathrm{N}=29)$ showing the least regard for "correct grammatical usage" and "logical cohesion" (Kurz 1993: 16). 
Given that the mean ratings given to items varied across client groups (Kurz 1993: 15), it is useful to disregard for the moment the exact ratings given by any group of clients to a particular item and instead rank them according to the relative importance given to each. Applying this to the data reported by Kurz (1993: 15) yields the following table of results.

TABLE 1

Rank order of quality criteria derived from Kurz (1993: 15)

\begin{tabular}{|l|ll|ll|ll|}
\hline User group & \multicolumn{2}{l}{ MDs } & \multicolumn{2}{l|}{ Eng } & \multicolumn{2}{l|}{ CE } \\
\hline & $1=$ & Sense & 1 & Sense & 1 & Terms \\
& $1=$ & Cohesion & 2 & Terms & 2 & Sense \\
& 2 & Terms & 3 & Cohesion & 3 & Completeness \\
& 3 & Completeness & 4 & Fluency & 4 & Cohesion \\
& 4 & Fluency & 5 & Completeness & 5 & Fluency \\
& 5 & Voice & 6 & Voice & 6 & Grammar \\
& 6 & Grammar & 7 & Accent & 7 & Voice \\
& 7 & Accent & 8 & Grammar & 8 & Accent \\
\hline
\end{tabular}

Legend: MDs = Medical Doctors, Eng = Engineers, CE = Council of Europe meeting.

It is notable that there is a high degree of homogeneity across these results. "Sense consistency with the original," "correct use of terminology" and "logical cohesion" appear consistently among the top four items across all samples. Similarly, the three lowest ranked items are always "pleasant voice," "grammatical correctness" and "native accent," albeit in a different rank order each time. Of the remaining two items, the mean score assigned to "fluency" meant that it was consistently ranked as an item of medium relative importance whereas the importance given to "completeness of information" varied widely across samples. For the attendees at the Council of Europe meeting, "completeness of information" was given the third highest mean rating, above even "logical cohesion." The mean score given to "completeness of information" by delegates at the engineering and medical conferences was far closer to the scores assigned to "fluency." This suggests that the respondents in these studies placed greater emphasis on the linguistic content of interpreted versions over the way that this content is delivered, even to the point of giving grammatical correctness a reduced level of importance.

A year after Kurz's first paper (1989), two papers were published that also attempted to further understanding of client views on interpreting. The paper by Daniel Gile (1990) departed from Kurz's example in two ways: instead of asking what clients expected of interpreters, Gile asked them to judge the quality of interpreting they had heard. He also decided to adopt different criteria to Kurz, opting for what he called "more global" criteria instead of Kurz's more specific ones (1990: 67, my translation). Thus, instead of Kurz's eight criteria, Gile presented the clients with 5 main items: general quality of the interpretation; linguistic output quality; terminological usage; fidelity; and voice, rhythm and intonation. Respondents were asked to score these out of 5, where 1 represented "very poor" and 5 represented "very good" (Gile 1990: 67, my translation). 
Gile's results show an even greater degree of consistency than those of Kurz. Of the 23 respondents, the vast majority scored each of these criteria at 4 or above, with the 5 American respondents giving every criteria a score of 5 (Gile 1990: 70). Thus it is not possible to produce a similar rank order table to the one produced to summarise Kurz's results. However, even if this were possible, the reduction in the number of criteria and the difficulty in mapping "general quality of interpretation" and "linguistic output quality" onto Kurz's criteria would render a direct comparison of results impossible. It is very difficult therefore to draw any conclusions from Gile's results, as he himself admitted (1990: 69).

The other study done in the same year took yet another approach. Moving away from the use of scales, Meak (1990) presented respondents with a series of 9 questions, varying from open ended, such as question 4 "in a table, what are the data that are vital to indicate?" (1990: 11, my translation), to the very closed, such as question 1 "does simultaneous interpreting allow you to follow a medical conference in which you do not understand the working languages?" (1990: 9, my translation). Unlike Gile (1990) and Kurz (1989), she included questions on aspects that are specific to interpreting at medical conferences such as the importance of medical titles and hospitals and whether individual medical fields require specific precision.

Meak's study showed that, despite her small sample size of only 10 doctors (1990: 8), responses to most questions varied widely, perhaps due to the different motivations for attending medical conferences. When asked whether simultaneous interpreting allowed them to follow the conference, eight respondents agreed that it did, while the two who disagreed justified their answer based on the perception that interpreters did not understand the subject matter fully and so their audience had to reconstruct what was actually meant. This suggests that prior experience of interpreting might also have been a factor in their responses. Meak's study therefore should be read as offering a snapshot of the variety of opinions clients might hold on interpreting, rather than giving a statistical or quantitative account of how common these opinions might be.

The study carried out by $\mathrm{Ng}$ Chin Bee (1992) adds further factors that may explain client expectations. The main aim of this study was not the discovery of client expectations but instead to compare the performance of student interpreters with previous work outlining the common problems in this language pair (1992: 35). Since the analysis of client expectations was not the aim of Ng's study, the most useful data in the context of this paper are those covering respondents' overall views on the performance of the interpreters.

One of the clearest results in Ng's study is that clients attributed any lack of clarity in the interpreted output to issues with the interpreters and not with the source text (1992: 37). In addition, a gender difference is evident in the results. Male respondents tended to place great importance on delivery style and the projection of confidence; while female respondents commented more on grammatical structures and politeness, leading to a marked difference in the how they ordered each of the five interpreters in terms of the quality of their output (1992: 38). As Ng points out, the fact that there was only one male interpreter and that he was ranked as the "best" interpreter by the men and the "worst" by the women, means that gender-based vocal preferences cannot be ruled out (1992: 38). Thus, in this study of clients' responses to interpreting provided outside of an authentic conference, gender-bias did seem to 
be related to quality judgments. This suggestion remains to be explored more fully. In addition, contrary to earlier results in client expectations, this study seems to suggest that non-lexical criteria, such as delivery and confidence, may play a part in quality judgments, especially among Japanese clients.

The four studies listed above therefore represent four very different methodological setups. Kurz's studies $(1989 ; 1993)$ attempt to elicit client expectations of the interpreting they were about to receive at a specific conference. These will therefore be termed "contextualised expectations" from this point onward. Meak, rather than query respondents at a conference, administered her questionnaire to ten doctors who "had good experience of international conferences" (Meak 1990: 8, my translation). Thus, their responses will necessarily be based on generalised and uncontextualised experience. They can therefore be termed "uncontextualised expectations." Gile's study presented a further approach by asking respondents to rate the interpreting they had received at a specific conference (1990: 67). This will therefore be termed "contextualised response." Lastly, Ng's study represents a fourth option by asking potential clients to assess pre-recorded interpreting (1992: 37). This will therefore be referred to as "uncontextualised response."

These four studies suggest that, even at this early stage in client research, there were two distinct axes along which studies could place themselves. The first is the axis of contextualisation, which allows differentiation between studies carried out in situ at live conferences and studies carried out in the laboratory using pre-recorded interpreting of one kind or another. Given the possibility that researchers could, if they wished, create mock conferences that existed only for the purposes of research or use output interpreted at a previous conference and not produced simply for the requirements of a study, this axis is a continuum and not a strict dichotomy. The second axis is much more of a dichotomy, opposing clients' expectations of interpreting they will receive with their response to the interpreting they have received. These axes allow the classification of these studies into the table below, the labels of which will be used to examine all other publications in this paper.

FIGURE 1

Arrangement of early studies according to their methodological approach

\begin{tabular}{c|c|c}
\multirow{2}{*}{ Meak (1990) } & $\mathrm{Ng}(1992)$ \\
\cline { 2 - 3 } Expectations & Kurz (1989; 1993) & Gile (1990) \\
Contextualised
\end{tabular}

These differences in approach taken would suggest that, even if all the scholars adopted the same data collection method and the same items $s^{1}$, it would be difficult to reconcile their results. Quite simply, clients' general expectations of interpreting may well be very different to their specific expectations of the interpreting at a given event. Similarly, their response to interpreting at a specific conference, which they are attending for particular reasons, may well differ from their rating of the interpreting that they have heard in a laboratory or at home. This is a point that will serve as the basis for much of the discussion in this paper. 
As explained in the introduction to this thesis, the focus is contextualised expectations, placing it more in line with the work carried out by Kurz (1989; 1993). However, this does not mean that the work found in the other three quadrants of the above table can be simply ignored. Even though there will be marked issues around the comparability of results from one approach to another, results generated by other approaches may help to clarify or question the results generated in contextualised client expectation work. In fact, it will be argued later in this paper that clients' uncontextualised expectations do seem to exert an influence on their expectations of interpreting in a specific context.

Returning more directly to the historical development of client expectations work, the year immediately following the publication of Kurz's piece (1993) saw an expansion in the variety of users surveyed with Kopczyński's study (1994) of the uncontextualised expectations of experts in the humanities $(\mathrm{N}=20)$, respondents working in Science and Technology $(\mathrm{N}=23)$ and diplomats $(\mathrm{N}=14)$, covering a total sample of 57 (1994: 91). This would mean that even the largest of Kopczyński's samples was smaller than any previous sample in a study of uncontextualised expectations. This paper would also offer yet another method further to those already mentioned, pioneered by Kurz, Gile, Meak and $\mathrm{Ng}$, with the researcher asking respondents to indicate what they saw as the three most important functions of interpreting in order of importance, before stating their top three principal annoyances and then their views on the role of the interpreter (1994: 92). In addition to dividing the results according to the professional background of the respondents, Kopczyński also divided the results according to whether respondents were primarily speakers or audience members at conferences (1994: 91).

The functions of interpreting most often given as the most important and second most important varied little according to professional grouping or even between speakers and audience members. Between $70 \%$ and $80 \%$ of members of each group felt that giving "detailed content" of the source text was the primary function of the interpreter and at least $60 \%$ of respondents felt that "terminological precision" was the second most important function (Kopczyński 1994: 93-94). Only in the matter of the third most important function was there a wide variety of responses with "style," "grammatical correctness" and "fluency of delivery" all being suggested by at least $20 \%$ of respondents in any given group (Kopczyński 1994: 93-94).

The picture that emerges from Kopczyński's work then is of a view of interpreting that is highly focussed on the transfer of linguistic and terminological information. This is underlined by the fact that among every group of respondents, no matter whether they were speakers or audience members, and regardless of their professional background, "faulty terminology" was most commonly named as the greatest annoyance (Kopczyński 1994: 95-96).

However, the results showing clients' impression of the role of the interpreter would seem to undercut any attempt at a simplistic interpretation. While a majority of respondents in every group, including speakers and audience members, agreed that interpreters should "remain in the background," more than $89 \%$ of members of the same groups felt that interpreters should "empathise with the speaker's intentions." The humanities scholars were the only ones who did not indicate a majority in favour of the interpreter imitating the speaker's tempo (Kopczyński 1994: 97-98). At the very least, this would seem to show a measure of awareness that there is much 
more to interpreted communication than simply speaking words. More importantly, this paper suggests that there may be a difference between stereotypical views of interpreters and how clients actually expect them to behave. As will be argued in the examination of the work of Diriker (2004) and Eraslan (2008; 2011), this division offers a useful starting point for future research.

While 1994 demonstrated the continued ability of scholars to innovate and design new research instruments to discover and analyse client expectations, papers in 1995 tended towards achieving more in terms of the scale of surveys attempted and in terms of making explicit the issues surrounding their analysis. Exemplary in the former shift is the survey compiled by Peter Moser (1995) under the auspices of the Association Internationale des Interprètes de Conférence (AIIC - International Association of Conference Interpreters). This contextualised expectations and response survey would gather an unprecedented 201 responses and would require the efforts of 91 interpreters to carry out the survey by structured interview (1995: 46-47). These interviews covered participants across 85 conferences, from large technical conferences to small general conferences. Innovations were also made in the survey items used as, for the first time; respondents were given a large number of open-ended questions on top of the traditional multiple-choice items, allowing them to express their views on interpreting in their own terms (1995: 28-39).

Interestingly, the results of this survey seem to support the same marginally linguistically-driven view of interpreting that was seen in Kopczyński's (1994) study. Not surprisingly, the most commonly voiced expectation of interpreting was that it be accurate, with questions of delivery, such as vocal and rhetorical skills, being mentioned less often (Moser 1995: 8). In addition, when asked what they thought would be particularly difficult about the interpreting profession, issues around "concentration" and "updating knowledge" were mentioned by $29.9 \%$ and $22.9 \%$ of respondents respectively, with only $7.5 \%$ mentioning the interpreters need to be a cultural mediator or performer. Still, like Kopczyński's study (1994), there were some responses that seemed to go against a strictly linguistic view of interpreting. The clearest among these was the fact that respondents tended to want interpreters to concentrate on the "essentials" of what was said, rather than trying to interpret everything and this preference was even more marked among older respondents (Moser 1995: 14-15). Thus, at least some freedom is given to interpreters to summarise what has been said, perhaps due to the awareness of the demands on interpreters' concentration, mentioned above.

However, the small number of respondents at any given conference (Moser 1995: 5) means that these results are necessarily of a general, global nature. Apart from categorisation of conferences by size and whether they were "technical" or "general" (1995: 7) there was little possibility to perform any close analysis of the relationship between a given conference and the expectation of the clients who attended it. This is especially true for conferences where only 1 or 2 clients were surveyed (1995: 6).

A similar problem is found in the work of Mack and Cattaruzza (1995), whose paper on contextualised expectations and experiences at five different conferences marks the second significant change in client expectation research of that year. The sample sizes from the conferences they researched ranged from 20, at a conference on European trade cooperation to 10 at a meeting on chemistry and medicine (1995: 39-41). They returned to the multiple-choice approach, adopting an identical research 
instrument to Vuorikoski (1993). What is striking about their results is just how similar the ratings of their six categories were across both expectations and experience for all client groups at all conferences. As far as client expectations are concerned, all categories received mean ratings of between 3.5 and 4.5, with the exception of the mean rating given to fluency by those who were first time users, which was just below 3.5 (1995: 43-45).

The results clearly show therefore that the survey was not powerful enough to be able to distinguish any real differences in clients' views. It is awareness of this problem that marks out Mack and Cattaruzza's work as so important in contextualised client expectation studies. Of all the studies carried out, theirs was the notable for its engagement with the theoretical issues by the client expectations research (Mack and Cattaruzza 1995: 38). It is their conclusion, however, that particularly merits attention. They conclude their paper with the following words:

Better coordination in the carrying out of surveys and an interdisciplinary approach in evaluating their results could bring about more reliable and valuable information on users' perception of SI [simultaneous interpretation] and their expectations. However, this kind of study by itself is unlikely to provide any viable theoretical outlook, as it cannot compensate for the underlying, fundamental lack of clearly defined and weighted quality components. (Mack and Cattaruzza 1995: 47)

These words clearly signal two of the most fundamental issues in all expectation and response research. The first issue is methodological: according to Mack and Cattaruzza (1995), the lack of reliability in the results of their instrument stems from the need for an "interdisciplinary approach" to research in this area. This seems to suggest a need to import methods from disciplines where the protocols surrounding the use of surveys are more established.

The second issue covered in their conclusion above is the need for a theory that can offer "clearly defined and weighted quality components" (Mack and Cattaruzza 1995: 47). The implication in this statement is that the lack of clarity in their results probably stems from confusion on the part of the respondents as to what the items used in their survey actually refer to. After all, these categories were invented by Interpreting Studies scholars and not interpreting users. Thus, it is no surprise that respondents had "difficulties ... in assessing SI ... in categories generally irrelevant to their everyday life” (1995: 45). Mack and Cattaruzza's study stands out as the first study where real doubt was expressed about the reliability of the items used and where the production of a new theory was offered as a possible solution to this.

These same considerations would be raised once more in the work of Vuorikoski (1998), who summarised much of the work that had gone on before that date and placed it in the context of skopos theory and the discourse analytical work of Hatim and Mason (1997; Vuorikoski 1998: 188) Thus, she considers the hypotheses made that expectations may be specific to different meeting types as an instantiation of skopos theory before questioning it in the light of the consistency of clients' interest in "faithfulness" and the contrary trend for expectations to vary among the audience of a given conference and even at different stages of the same event (1998: 188-189). Following Mack and Cattaruzza's (1995: 47) observations on the weaknesses of the research tools available at the time, Vuorikoski also expresses both doubt in the power of the research instruments used and the need for new instruments to be created in the light of improved theorisation (1998: 190). Thus, the theme that runs through 
this paper is the theme that has emerged from much of the work carried out in this first period of research: "in order to serve their purpose, quality concepts have to be clearly defined" (1998: 190). These themes and the theoretical concerns expressed by Vuorikoski would be echoed in a paper that, to date, represents the most thorough examination of work to elicit client expectations. This work will be the focus of the next section of this paper.

\subsection{The first Major Review of Client Expectations Research}

In many ways, Kurz (2001) represents the high water mark of the approaches mentioned above to client expectations research and indeed for attempts to link it to wider matters of interpreting quality. Kurz also attempted to contextualise this work not only by providing a theoretical justification for its existence but also by framing it in the history of conference interpreting research. Where this present paper differs from the work of Kurz is that she chose to arrange her review in an author-centred fashion, allowing comparisons to be made between the different approaches and methods of different authors (Kurz 2001: 396-403). In this present paper, however, research has been arranged chronologically, in order to give a greater impression of the trajectory of research since the late 80s. As later sections will show, this chronological approach also allows a closer examination of the reasons behind significant changes in this trajectory in the last decade.

As far as the history of interpreting research is concerned, Kurz (2001: 396-397) points out that client expectations research forms part of a larger concern with the definition and measurement of translation and interpreting quality. However, despite the fact that interpreting scholars were aware of the importance of the professional background of their audiences from the earliest days of interpreting research in the 1950s, it was not until 1989, some 37 years after it was first posited that different users might have different requirements, that the first empirical study was carried out to investigate if this were true (2001: 396).

What is more interesting and more surprising than Kurz's historical contextualisation of client expectations research is the theoretical framework in which she situates it. While previous scholars had opted to use theories from Translation Studies such as skopos theory (Mack and Cattaruzza 1995: 38; Vuorikoski 1998: 188-189) or discourse analytical frameworks (Vuorikoski 1998: 188), Kurz preferred instead to justify client expectations research with appeals to marketing and Total Quality Management (2001: 394-395, 404-405). Interpreting in this view is seen as a product or service much like any other and the need for client feedback then stems from the realisation that quality, at least from the buyer and client's point of view, is a subjective measurement of the difference between what the client expected and the service they actually received. It almost goes without saying that it is likely to be this measurement of quality and not any measurement derived from expert analysis or the judgment of other professionals that will play a large part in negotiating better pay and conditions for interpreters.

Viewed in this light, it is apparent that the greatest need for client expectations work is the creation of a generally acceptable, extensible research tool that can be consistently applied to a wide variety of situations. However, as has already been shown in the previous section, consistency is not something that was the hallmark 
of client expectations research in its infancy. In Kurz's view, this lack of consistency led to a corresponding lack of comparability between studies, despite the fact that all client expectations studies had used surveys or structured interviews as data collection methods (2001: 397-398). This problem is further compounded by the lack of agreement over whether expectations or experience or both are the most opposite perspectives from which to study the views of clients.

This lack of comparability can lead scholars in two directions. The first of these is to follow those who, like Shlesinger (1994), express doubt in the viability and usefulness of client expectations studies. As Kurz points out and as has been discussed above, several factors besides the linguistic output of the interpreter may affect user's perception of quality and some parts of interpreted texts may be subject to greater scrutiny than others due to their own interests (2001: 403-404). The natural reaction to this would be to conclude that only interpreters are qualified to judge the success of an interpreted text. The alternative to this view is the one expressed at the beginning of this paper: namely that that user's perceptions can never be an objective measure of quality (if such a thing is ever possible anyway) but that this does not mean that they can simply be disregarded. On the contrary, it means that interpreters need to be aware of client expectations and do their best to meet these, whilst being aware that not all expectations will be possible or reasonable to fulfil (see Kurz 2001: 404).

Kurz's review of the work done before 2001 therefore serves as both a critical summary of the state of the field at that time and an encouragement for ongoing work. As Kurz points out, client feedback, while being only one of a number of necessary perspectives on the interpreting actually delivered at a given conference, offers information that can be useful both for practising interpreters and interpreting trainers (2001: 407). However, this does not gloss over the pressing need at that point for greater methodological rigour and for theorisation that can explain or predict the data produced by such methods (2001: 397, 403). The next section will therefore examine the work that took place in client expectations research after the publication or Kurz's meta-analysis, including further analyses of the shortcomings and promise of research in this area.

\subsection{The Twenty-first Century: Decline, Debate and De-/Re-contextualisation}

If the publication of Kurz's (2001) review of expectations research was an encouragement to greater methodological rigour and further in-depth work on client expectations, then it apparently received little in the way of response. A search through the major research aggregators for conference interpreting such as Daniel Gile's CIRIN website (2015) and for Translation Studies as a whole such as Translation Studies Abstracts (St. Jerome Publishing n.d.) shows that, at least as far as work in English and French is concerned, the period between 2002 and the present was one in which client expectations work declined in prominence. In total, only 3 attempts to elicit new data on contextualised client expectations appear in either database or in Google scholar in this period in English or French, none of which appear in translation or interpreting journals. Instead, such work became part of larger projects, ranging from a PhD thesis ${ }^{2}$ (Eraslan 2011), a monograph on the context of conference interpreting ${ }^{3}$ (Diriker 2004), and a paper from conference proceedings (Eraslan 2008). 
What is interesting is that the relationship between these pieces of research and previous work on client expectations is unclear. Diriker, for instance, only mentions previous client expectations studies in passing, preferring to emphasise the problematic relationship between the context that client expectation studies have sought to describe and the actual behaviour of interpreters at specific conferences (2004: 13). Similarly, client expectation studies receive only passing mentions by Eraslan (2008: 7; 2011: 25) and in both cases she argued that there was a difference between work that sought to elicit client expectations as regards the quality of interpreting and work on clients' expectations of the interpreter's role.

This latter distinction forms a useful starting point from which to explain why there seems to have been a sudden decline in the number of contextualised client expectation studies in English and French after the publication of Kurz's (2001) survey of the state of the field. If Eraslan's (2011: 25) "quality" versus "role" division is valid, then this suggests a difference in the epistemological stance taken towards interpreting itself. The uncontextualised and depersonalised notion of "quality" suggests, in its connotation of the worlds of industry and commerce, that interpreting is a product that can be judged against a series of objective and measurable criteria that are defined and operationalized outside of any given context (Chiaro and Nocella 2004: 281; Kurz 2001: 394). This leads to the challenge of defining and delineating exactly what is meant by quality and how this can be measured with any degree of accuracy. Moser-Mercer, for example, states that:

The first step in the measurement of quality is therefore to distinguish the construct from other similar constructs by defining it clearly, precisely and unambiguously.... We must therefore decide how we can elicit responses that will indicate the degree of presence or absence of a specific construct attribute in the minds of our respondents. (Moser-Mercer 2008: 146)

The assumption here is that quality is not only a construct that can be given an objective definition but that can have a presence or absence independent of any particular context. Quality in these terms, while evaluated in the minds of respondents, nonetheless exists as a construct independently of these minds. While seeing quality in this way does encourage increased rigour in research - Moser-Mercer goes on to assert that "most of the research on quality lacks a rigorous description of the construct quality and [...] we continue to search for quality concepts that can be operationalized" (2008: 146, italics in original) - the problem with research on quality in these terms is very similar to the problem with work on uncontextualised expectations and work on interpreters' definitions of quality. All three represent uncontextualised ideals of interpreting that may not be applicable to particular situations and even if they are, they are likely to be reinterpreted, in a hermeneutical sense, in each case.

A useful illustrative example of this is the contrast drawn by Diriker between the "meta-discourse" (2004: 25-50, 131-147) clients used to describe simultaneous interpreting in general and their actual expectations of how interpreters would behave at a given conference. At the conference she studied, despite the fact that apparent client expectations seemed to be very homogenous, with most of the clients she interviewed stating preferences for "fidelity to the meaning of the speaker's speech" and "familiarity with the topic and terminology," these same concepts were understood very differently by different clients (2004: 136). This contradiction led to 
interpreters having to negotiate their position using both linguistic and social strategies $(2004: 135,137)$. In addition, despite the opinions expressed by Turkish society, experts in interpreting, interpreters' own writings (2004: 25-50) and by one of the interpreters (2004: 71) that interpreting is about accurately delivering what was said without any additions or omissions, interpreters actively shaped communication in several ways. These included giving speakers advice on how to work more effectively with interpreters and interrupting the interpreting of the speeches to notify listeners when something had gone wrong or when speakers were making it difficult to interpret.

The applicability of the work on client perceptions of quality to any particular case of interpreting is therefore highly debatable, especially given the possibility, pointed out by Diriker (2004: 136-137), for the terms used in surveys or interviews to be interpreted in a variety of different ways. This problem, combined with the fact that the waning of interest in contextualised client expectations roughly coincides with the rapid growth in the number of studies on the social aspects of interpreting ${ }^{4}$ suggests that work on client expectations of the role of the interpreter, rather than work on client's views on quality in general, should have come to the fore. Yet, as was discussed earlier, the number of publications on client expectations in conference interpreting actually dropped in the years after Kurz's (2001) review paper.

On the one hand, given both the implicit (e.g., Shlesinger 1994; Chiaro and Nocella 2004: 281) and explicit criticism (e.g., Moser-Mercer 2008) of client expectations work, such a reduction in interest may be perfectly understandable. As this paper has already shown, the range of methods, approaches and even aspects of quality covered in the work done made it difficult to carry out comparative work and almost impossible to reach any firm conclusions as to what had been discovered so far. In this context, and bearing in mind Diriker's previously mentioned findings on the variety of meanings given to similar phrases (2004: 136), it is impossible to agree with those who assert that work on client and interpreter views on quality has produced largely homogenous results (e.g., Al-Zahran 2007: 4, 67-68). Much of the previous work in client expectations then has provided a snapshot of the potential of this work rather than providing evidence of its realisation.

On the other hand, wider shifts in Interpreting Studies might also have contributed to the waning of interest in client expectations of interpreting. The 1990s and 2000s saw a marked growth in work on the role of interpreters in non-conference settings and especially on how they co-produce interpreted texts in partnership with the other participants in the interpreting situation (Pöchhacker 2004: 78-79). One of the most wide-ranging examples of this is the collection of works edited by Ian Mason (2001), entitled Triadic Exchanges, which covers the role(s) played by interpreters in a variety of community settings from the launch of a bank in Africa (2001: 109-130) to therapy sessions (2001: 71-86). In all these cases, it is the creation and performance of the interpreter's role in a specific instance of interpreting that is in view rather than clients' views of this role. One example of a departure away from this general trend is the work of Wadensjö who integrated transcribed data, interviews, participant observation and a range of other qualitative sources into her analysis of the social norms and behaviours of community interpreters (1998: 94). This increase in work in community interpreting and the parallel increase in interest in text-based work on the realisation of the interpreter's role as opposed to clients' expectations of 
this role both seem to mitigate against work on expectations of conference interpreting clients maintaining a position of great influence in Interpreting Studies.

A combination of these two factors - criticism of previous work and the preference for text-based analysis of specific interpreting situations - may be at work in the relative decline of client expectations and response research, at least in the form that it had taken in the 80 s and 90s. In this context, what is notable about the three studies that were carried out after the publication of Kurz's (2001) review paper is that they were able to show that the previous methods of eliciting client expectations surveys and interviews - could be paired up with the kinds of textual analysis that were characteristic of much of the socially-oriented work of the 90s and 2000s. Diriker's study (2004), for instance, brings together interviews with interpreters, conference organisers, speakers and users alongside deep analyses of the interpreters' output. Similarly, Eraslan combined user surveys, interviews with interpreters and analyses of interpreter outputs. The earlier methods, as used in the $80 \mathrm{~s}$ and $90 \mathrm{~s}$, were therefore used to supply one piece of a much larger picture of the contextualisation of the role(s) of interpreters, much in the same way as Wadensjö (1998: 94) brought together a range of data sources in her analysis.

The work of Diriker (2004) and Eraslan $(2008 ; 2011)$ therefore reveals a much more nuanced picture of client expectations than was previously available. For a start, as previously mentioned, Diriker (2004: 136) points out that the capacity for the same key concepts to mean different things to different audience members means that even where clients appear to agree on what they want from interpreters at a specific conference, their understandings of what this entails may differ markedly. More subtly, she suggests that the way the profession is presented in public, which she calls the "meta-discourse" of conference interpreting (2004: 25-50), may itself be a factor in client expectations. By simplifying the presentation of the work of conference interpreters down to the transfer of meaning communicated by the source text speaker while remaining objective (2004: 48-49), interpreters may reinforce a certain impression of their profession that goes on to be reflected in clients' expectations of their work. The view that conference interpreters tend to give the impression that their role is to be invisible agents of meaning transfer is supported by the fact that, in the work of Angelelli, the conference interpreters in her sample gave lower scores for items regarding their "visibility" than court or medical interpreters (2004: 72-73).

The suggestion that this simplified impression of interpreting as objective information transfer is reflected in some areas of client expectations gains even more credibility in the work of Eraslan, who sought to demonstrate the difference between two areas of clients' expectations. This first is the "normative role" (Eraslan 2008: 11), which involves "fidelity to the original speech," use of correct terminology and rendering every detail of the original as well as neutrality. This bears a striking resemblance to the impression of interpreting reflected in Diriker's (2004: 25-50) elucidation of the "meta-discourse." However, these expectations are reinterpreted according to the needs of the specific conference, becoming the "typical role" (Eraslan 2008: 11). This "typical role" therefore covers questions on how interpreters should deal with the names of foreign institutions, and whether they should correct the speaker if they have made a mistake or explain details in the event of misunderstandings.

Analysing expectations in this way allows for contradictions in client expectations to be noticed and explained. If "normative" expectations of interpreting are 
treated as being separate from those specific to a given conference, then it is not surprising that the majority of clients surveyed by Eraslan generally indicated that they would like interpreters to be "absolutely neutral and uninvolved" (2008: 20) and yet a majority also want interpreters to smooth communication by correcting speaker mistakes and adding explanations. In much the same way as clients might have different definitions of "fidelity" (Diriker 2004: 136), the role of interpreters may also be subject to reinterpretation in the context of a given conference.

Eraslan's proposed divide between "normative role" and "typical role" (2008: 11) therefore provides a lens through which previous research can be understood and the foundation for new research. In the case of previous research, the predominance of normative role items such as "sense consistency with the original," "logical cohesion" and "pleasant voice" (Kurz 1993) limits the usefulness of such work to the examination of audience views on this aspect of the interpreter's work. At the same time, the fact that these items all measure the same aspect of the interpreter's role means that similarities in how they are rated are only to be expected. Adding items that more directly relate to interpreters' practice in a given setting, such as how to handle names of job titles (see Meak 1990: 10) or whether interpreters should imitate the speaker's intonation (Eraslan 2008: 22) allows a much more nuanced view of clients' expectations. The price of this is that, since different events present different challenges for interpreters (see e.g., Gile 1989), not all event-specific items will be able to be used in all cases, thus problematizing the possibility for the results generated in different studies to be directly comparable across all items. However, future research may well indicate patterns and trends within these event-specific expectations that themselves facilitate some form of comparison.

\section{Conclusion}

This paper has demonstrated that, although client expectations studies have been carried out over the past 24 years, this does not mean that the results of such work are homogenous or clear. On the contrary, the wide variety of approaches and items used makes it very difficult to directly compare different studies. This lack of comparability seems to have contributed to a lack of momentum in client expectations work, leading to a marked decline in the number of studies published in English or French examining client expectations in the 21st century. Increasing interest in the social role of interpreters also seems to have led to a change in focus in Interpreting Studies, away from the examination of general accounts of the expectations that clients have towards interpreters toward examinations of their practices in specific settings.

It is therefore necessary to use an approach that allows the collection of data on clients' views on the stereotypical or normative view of interpreters, as well as their views of what they require in the specific setting in which they experience interpreting. This general view of interpreting, which seems to be only slightly affected by context (see Kurz 1993), must therefore be examined and understood separately from the more specific expectations of interpreters, which are, by definition, contextspecific. Much of the challenge of future work in client expectations will be in the search for models and methods that are flexible enough to cover both sets of expectations yet robust enough to generate clear results. In addition to the ability to classify 
expectations into different categories, as in the work of Eraslan (2008), it is therefore necessary to have an overarching theory in which expectations can be explained and perhaps even predicted, something that has been conspicuous by its absence in client expectations work, especially in its earlier periods (Mack and Cattaruzza 1995: 47; Moser-Mercer 2008: 146-147). An ability to predict expectations could then form the basis of managing and satisfying them.

\section{NOTES}

1. From this point on, in accordance with standard practice in fields where survey research takes place on a more systematic level, the word "items" will be adopted to describe the individual elements of each survey to which respondents are asked to reply. This avoids the confusion of referring to survey questions, criteria and such like when examining particular studies.

2. It is the minor dissertation - a report made in the middle of the $\mathrm{PhD}$ process - by this scholar that appears on Google scholar. However, since the $\mathrm{PhD}$ thesis represents the finished study, references are made to this and not the minor dissertation that preceded it.

3. This monograph is a publication of Diriker's $\mathrm{PhD}$ thesis, which is identically named. As it is only the monograph and not the thesis that appears when searching, only the former has been counted.

4. See Pöchhacker (2004: 36-37, 40-42, 44) who points out that, while work on the interpersonal and social aspects of interpreting, specifically community interpreting, was available at least from the 1980s, researchers in conference interpreting were ignorant of such work and it would take until 1995, and the first "Critical Link" conference, for this work to gain a foothold on the international stage.

\section{REFERENCES}

Al-ZAHRAN, Aladdin (2007): The consecutive conference interpreter as intercultural mediator: a cognitive-pragmatic approach to the interpreter's role. Unpublished $\mathrm{PhD}$ Thesis. University of Salford, United Kingdom. Visited on 23 August 2012, <http://usir.salford.ac.uk/2060/>.

ANGELELLI, Claudia V. (2004): Revisiting the interpreter's role: a study of conference, court, and medical interpreters in Canada, Mexico, and the United States. Amsterdam: John Benjamins. Visited on 22 November 2012, <http://books.google.co.uk/books?hl=en\&lr=\&id=Osc5Vz nIT1cC\&oi=fnd\&pg=PR11\&dq=\%22Revisiting+the+Interpreter\%E2\%80\%99s+Role: $+\mathrm{A}+\mathrm{St}$ $\mathrm{udy}+\mathrm{of}+$ Conference, + Court+and+Medical+interpreters $+\mathrm{in}+\mathrm{Canada},+$ Mexico,+and + the $+\mathrm{U}$ nited+States\%22\&ots=yVuNBdByvE\&sig=lKLTyvaJ71IrHd9IbRXITvOMhKk $>$.

BüHLER, Hildegrund (1986): Linguistic (semantic) and extra-linguistic (pragmatic) criteria for the evaluation of conference interpretation and interpreters. Multilingua. 5(4):231-235.

Chiaro, Delia and Nocella, Giuseppe (2004): Interpreters' perception of linguistic and nonlinguistic factors affecting quality: A survey through the world wide web. Meta. 49(2):278293.

DIRIKER, Ebru (2004): De-/re-contextualizing conference interpreting: interpreters in the ivory tower?, Amsterdam: John Benjamins.

Eraslan, Seyda (2008): 'Cultural Mediator' or 'Scrupulous Translator'? Revisiting Role, Context and Culture in Consecutive Conference Interpreting P. Boulogne, ed. Translation and Its Others. Selected papers of the CETRA research Seminar in Translation Studies 2007.

Eraslan, Seyda (2011): International Knowledge Transfer in Turkey: The Consecutive Interpreter's Role in Context. Unpublished PhD Thesis. Tarragona, Spain: Rovira i Virgili University, Tarragona, Spain.

GiLE, Daniel (1989): Les flux d'information dans les réunions interlinguistiques et l'interprétation de conférence: premières observations. Meta. 34(4):649-660.

GiLE, Daniel (1990): L'évaluation de la qualité de l'interprétation par les délégués: une étude de cas. The Interpreters' Newsletter. (3):66-71.

GILE, Daniel (2015): CIRIN: An International Information Network on Conference Interpreting Research (CIR). Visited on 8 April 2015, <http://cirinandgile.com/>. 
Hatim, Basil and Mason, Ian (1997): The Translator As Communicator, London: Routledge.

KoPCZYŃsKI, Andrzej (1994): Quality in conference interpreting: Some pragmatic problems. In: Sylvie Lambert \& Barbara. Moser-Mercer, eds. Bridging the Gap: Empirical research in simultaneous interpretation. Amsterdam: John Benjamins, 87-99.

KuRz, Ingrid (1989): Conference Interpreting: User Expectations. In: Deanna L. Hammond, ed., Coming of Age: Proceedings of the 30th Annual Conference of the American Translators Association. Medford, New Jersey: Learned Information, 143-148.

KuRZ, Ingrid (1993): Conference interpretation: expectations of different user groups. The Interpreters' Newsletter. (5):13-21.

Kurz, Ingrid (2001): Conference interpreting: Quality in the ears of the user. Meta. 46(2):394409.

Mack, Gabrielle and CATTARUzza, Lorella (1995): User surveys in SI: A means of learning about quality and/or raising some reasonable doubts. In: Jorma TommoLA, ed, Topics in Interpreting Research. Turku: University of Turku, Centre for Translation and Interpreting, 37-51.

Mason, Ian, ed. (2001): Triadic Exchanges: Studies in Dialogue Interpreting, Manchester: St. Jerome.

MEAK, Lidia (1990): Interprétation et congrès médical: attentes et commentaires. The Interpreters' Newsletter. (3):8-13.

Moser, Peter (1995): Survey on Expectations of Users of Conference Interpretation. Vienna: Association Internationale des Interprètes de Conference/ S R Z Stadt + Regionalforschung $\mathrm{GmbH}$.

Moser-Mercer, Barbara (2008): Construct-ing quality. In: Gyde Hansen, Andrew Chesterman, and Heidrun. Gerzymisch-Arbogast, eds. Efforts and Models in Interpreting and Translation Research. Amsterdam: John Benjamins, 143-156.

NG, Bee Ching (1992): End Users' Subjective Reaction to the Performance of Student Interpreters. The Interpreters' Newsletter. Special Issue 1:35-41.

PöchHACKer, Franz (2004): Introducing interpreting studies, London: Routledge.

Seleskovitch, Danica (1986): Comment: Who should assess an interpreter's performance. Multilingua. 5(4):236.

Shlesinger, Miriam (1994): Quality in simultaneous interpreting. In: Yves Gambier, Daniel GILE, and Christopher TAYLOR, eds. Conference Interpreting: Current Trends in Research. Amsterdam: John Benjamins, 123-132.

St. Jerome Publishing. Translation Studies Abstracts Online. Visited on 8 April 2015, <https:// www.stjerome.co.uk/tsa/>.

Vuorikoski, Anna-Ritta (1993): Simultaneous interpretation - user experience and expectations. In: Catriona Picken, ed. Translation - the Vital Link. Proceedings. XIIIth World Congress of FIT. London: Institute of Translation and Interpreting, 317-327.

VUORIKoski, Anna-Riitta (1998): User responses to simultaneous interpreting. In: Lynne Bowker, ed. Unity in Diversity? Current Trends in Translation Studies, 184-197.

WADENSJÖ, Cecilia (1998): Interpreting as Interaction, London: Longman. 